\title{
POETRY
}

\section{After the flood}

$\mathrm{He}$ is an old man, frail fingers like blind moths Grasping discarded, sooty dreams

An old man, with timeworn memories

"No, anything but the chest

Please, don't throw out anything until we find it"

He lunges at the trucks, whose maws chew all of his things

"You should wear gloves, Merv"

"I can't, I need to touch this"

Silt-scratched records that will never again play Music For Relaxation

Keys to nothing

Keys to everything

His pile of valuables includes HVAC tubing, tubes of acrylic paint, a "beer

on drought" sign, a record player, candle holders,

Keys keys keys

The surprising heaviness of a soaked book

Scrap metal pile

Is he a hoarder?

Or is this what my own life would spit up if soaked

through?

The intimacy of grabbing all of his personal things His precious things, smelling of staleness and rot

Relentlessly tossed

Every decade of childhood represented

The Cabbage Patch, a waterlogged Anne of Avonlea, the single Lego pieces

Massive swollen earthworm amid rusting nails

They will be the survivors of earth's deluge

As our planet boils and storms in frustration

We are wordless worker ants hauling

Loads and loads into yawning bins

Smiling over our masks with our eyes, not many words

Strangers united, just enough

Water roared ferociously through his home

But as the hot day pounds on us

A cool drink is all we want

Ah, watermelon. Refreshing like a cold dive.

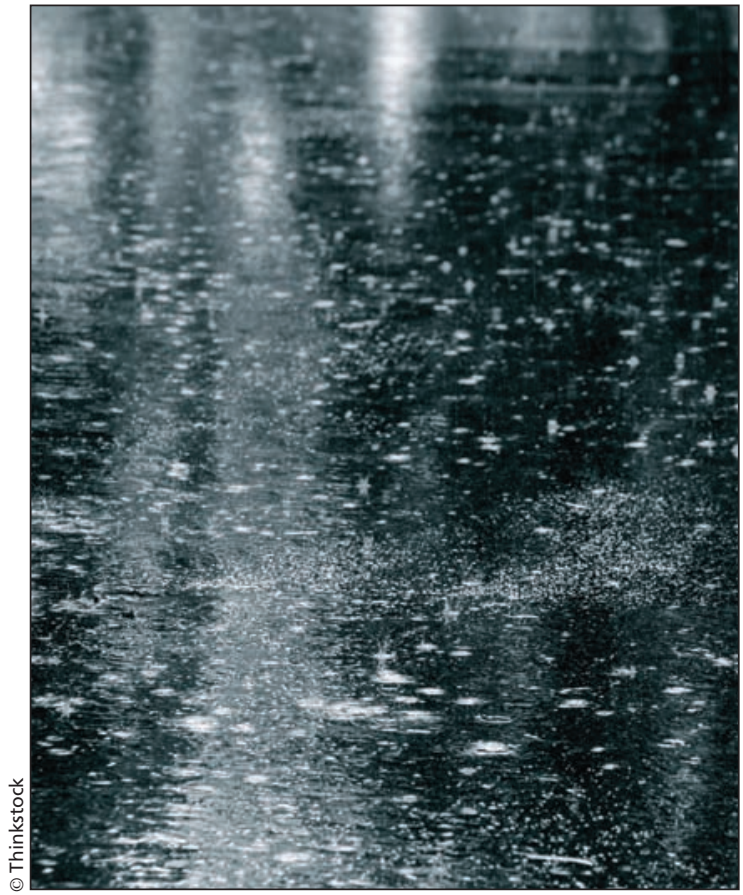

How does one become

Elderly, vulnerable, socially isolated Determinants of his health on garish display

Exposed naked in his own front yard Home alone, head heavy in his hands After the crowd disperses

He wanted us all to stay,

To tells us about the pieces that mattered

Hidden anguish

Half his world has been carted away

An old man watching his own wake

Where his things are deemed invaluable

And now they are gone

The stories forgotten, fading

He stares at discarded N95 masks, watermelon rinds, Remnants of his life,

And waits for the next flood

\section{Christine Gibson MD MMedEd}

Program Director

Global Health Enhanced Skills

Department of Family Medicine

University of Calgary

Calgary, Alta.

CMAJ 2014. DOI:10.1503/cmaj.131246 